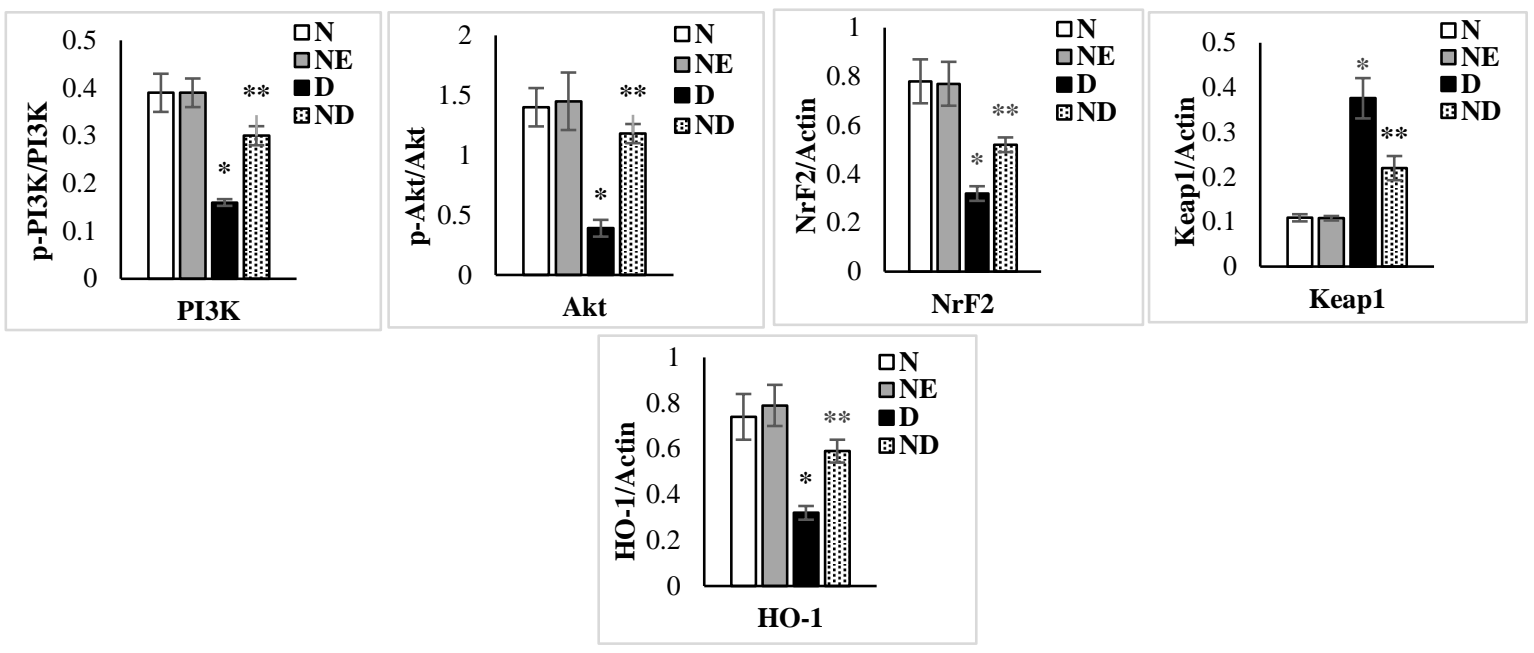

Figure S1. Densitometric analysis for the Western blot analysis of PI3K, p-PI3K, Nrf2, t-Akt, pAkt, HO-1, Keap-1; The values are expressed as the mean \pm SEM ( $n=3)$; columns not sharing a common symbol $(*, * *)$ differ significantly with each other $(* \mathrm{P}<0.05$ vs normal control, $* * \mathrm{P}<$ 0.05 vs DOX control). 


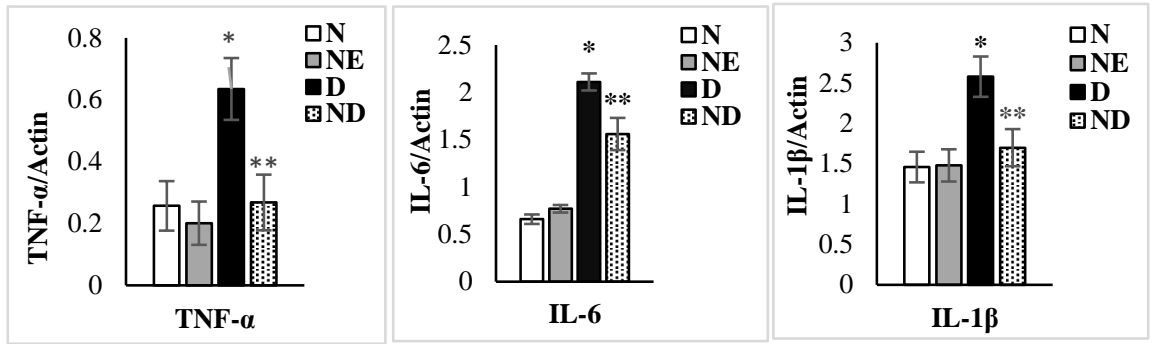

Figure S2. Densitometric analysis for the Western blot analysis of TNF- $\alpha$, IL-6 and IL-1 $\beta$; The values are expressed as the mean $\pm \operatorname{SEM}(n=3)$; columns not sharing a common symbol $(*, * *)$ differ significantly with each other $(* \mathrm{P}<0.05$ vs normal control, $* * \mathrm{P}<0.05$ vs DOX control). 


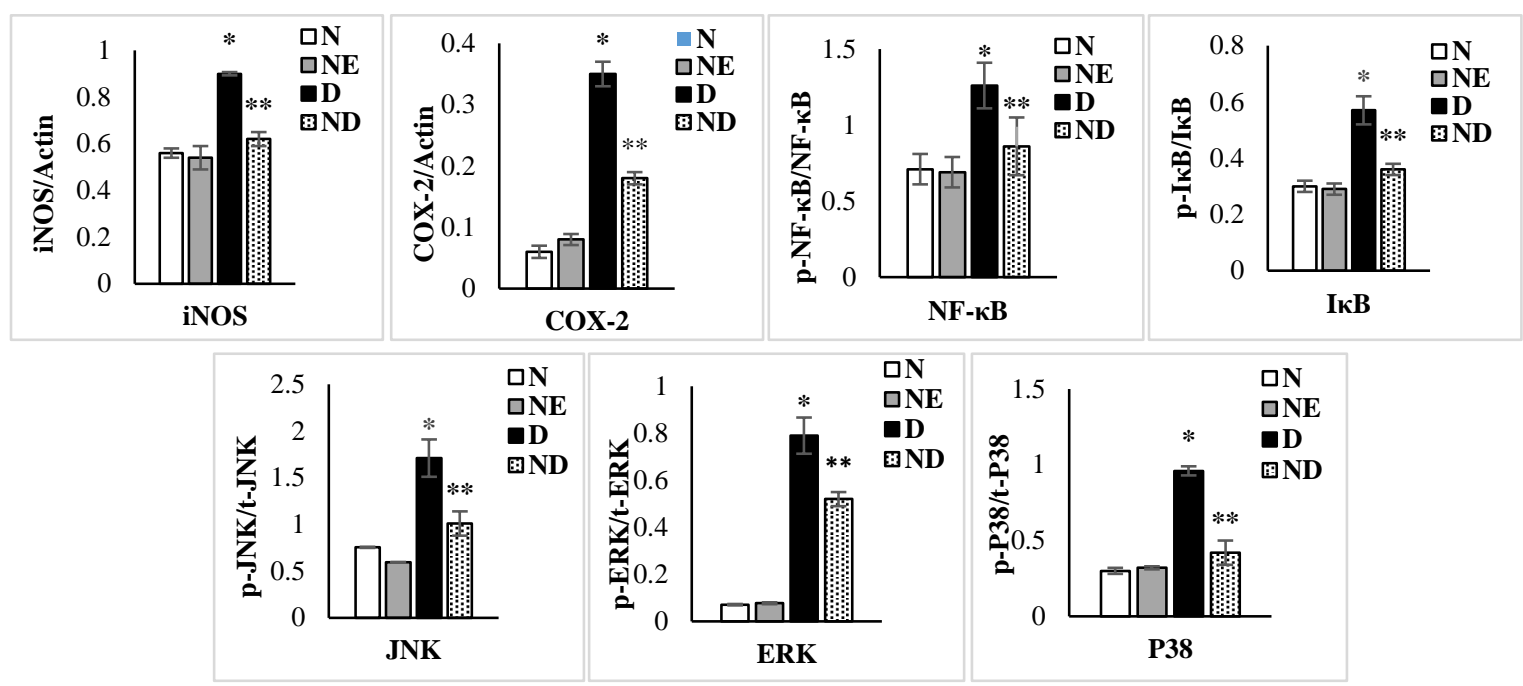

Figure S3. Densitometric analysis for the Western blot analysis of iNOS, COX-2, NF- $\mathrm{B}-\mathrm{P} 65$, p-

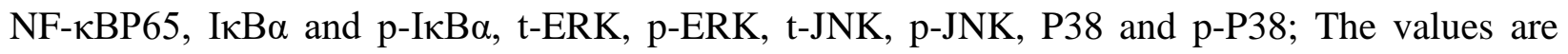
expressed as the mean \pm SEM $(n=3)$; columns not sharing a common symbol $(*$, **) differ significantly with each other $(* \mathrm{P}<0.05$ vs normal control, $* * \mathrm{P}<0.05$ vs DOX control $)$. 


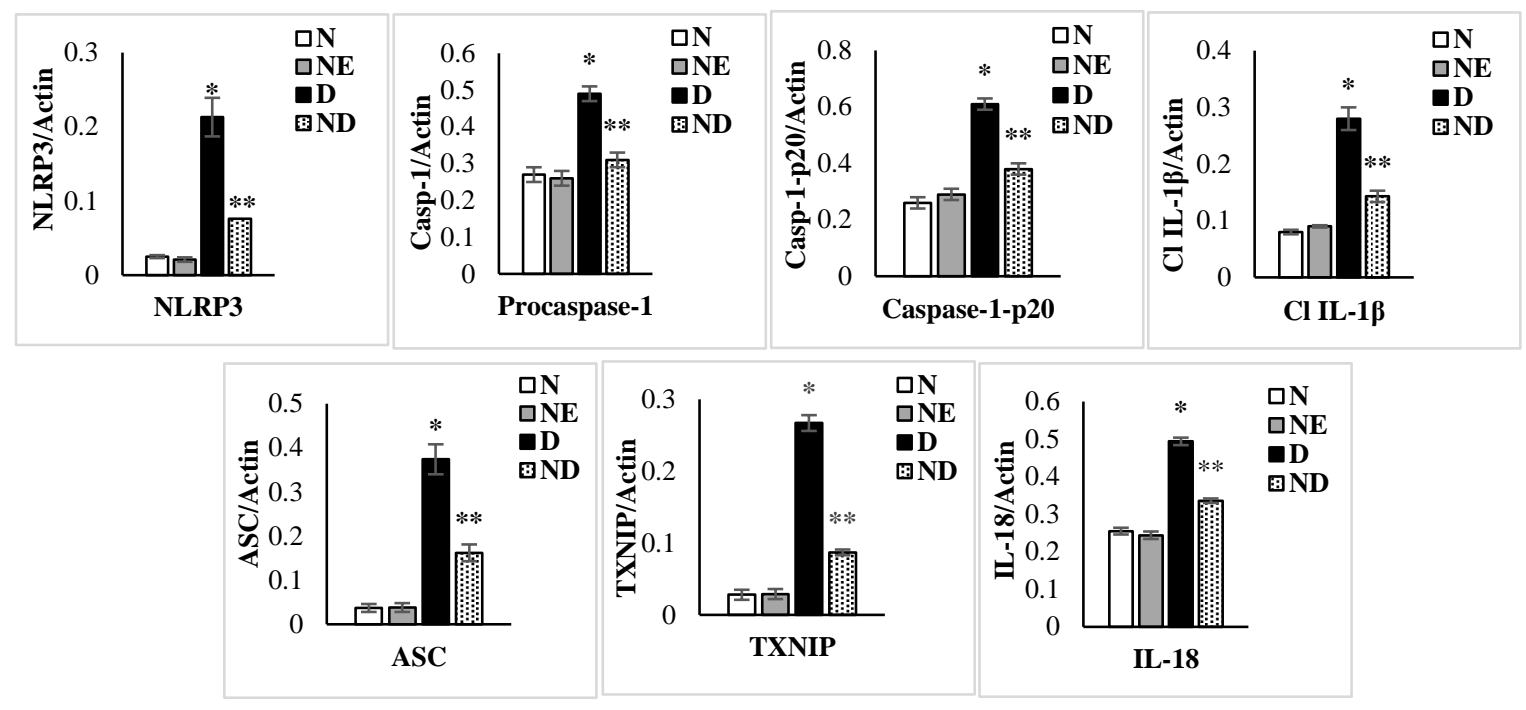

Figure S4. Densitometric analysis for the Western blot analysis of NLRP3, ASC, procaspase-1, caspase-1-p20, cleaved-IL-1 $\beta$ and IL-18; The values are expressed as the mean \pm SEM $(n=3)$; columns not sharing a common symbol $(*, * *)$ differ significantly with each other $\left({ }^{*} \mathrm{P}<0.05\right.$ vs normal control, $* * \mathrm{P}<0.05$ vs DOX control). 


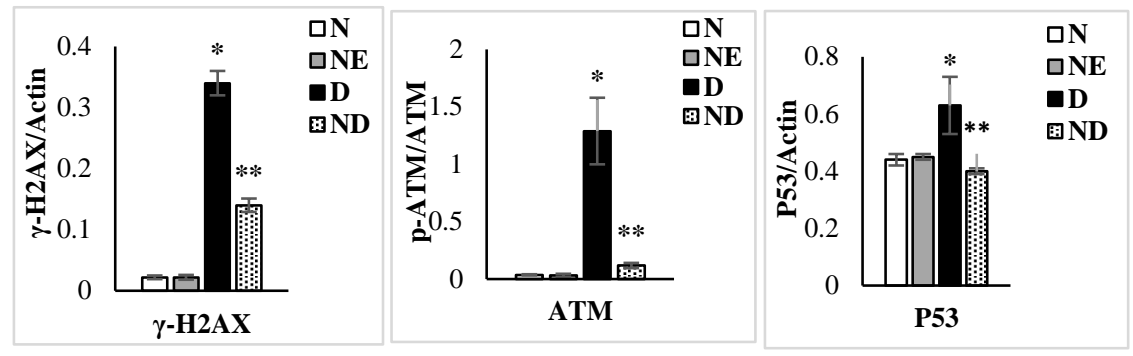

Figure S5. Densitometric analysis for the Western blot analysis of $\gamma$-H2AX, ATM, p-ATM and P53; The values are expressed as the mean \pm SEM $(n=3)$; columns not sharing a common symbol $(*, * *)$ differ significantly with each other $(* \mathrm{P}<0.05$ vs normal control, $* * \mathrm{P}<0.05$ vs DOX control). 


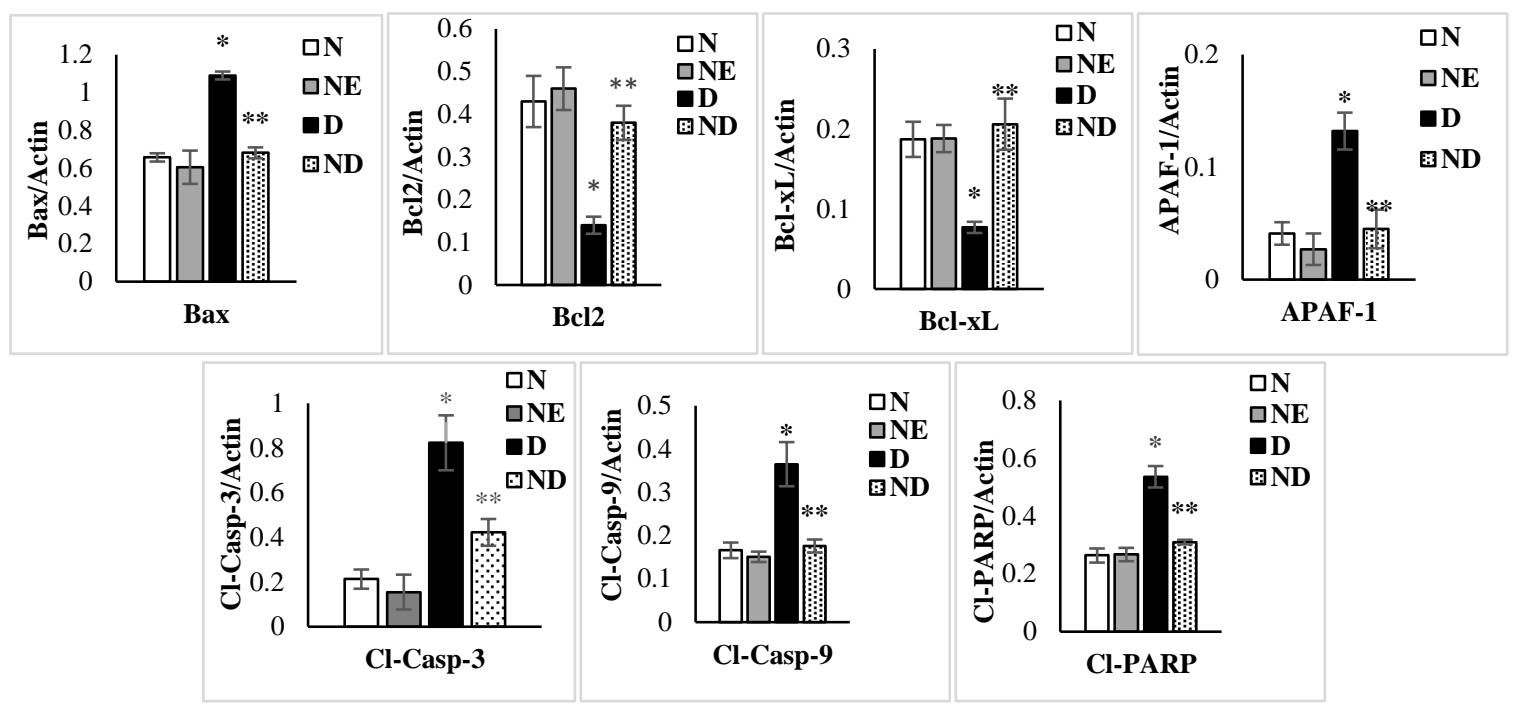

Figure S6. Densitometric analysis for the Western blot analysis of Bax, Bcl2, Bcl-xL, active caspase-3, active caspase-9, APAF-1, cleaved PARP; The values are expressed as the mean \pm SEM $(\mathrm{n}=3)$; columns not sharing a common symbol $(*, * *)$ differ significantly with each other $(* \mathrm{P}<$ 0.05 vs normal control, $* * \mathrm{P}<0.05$ vs DOX control). 


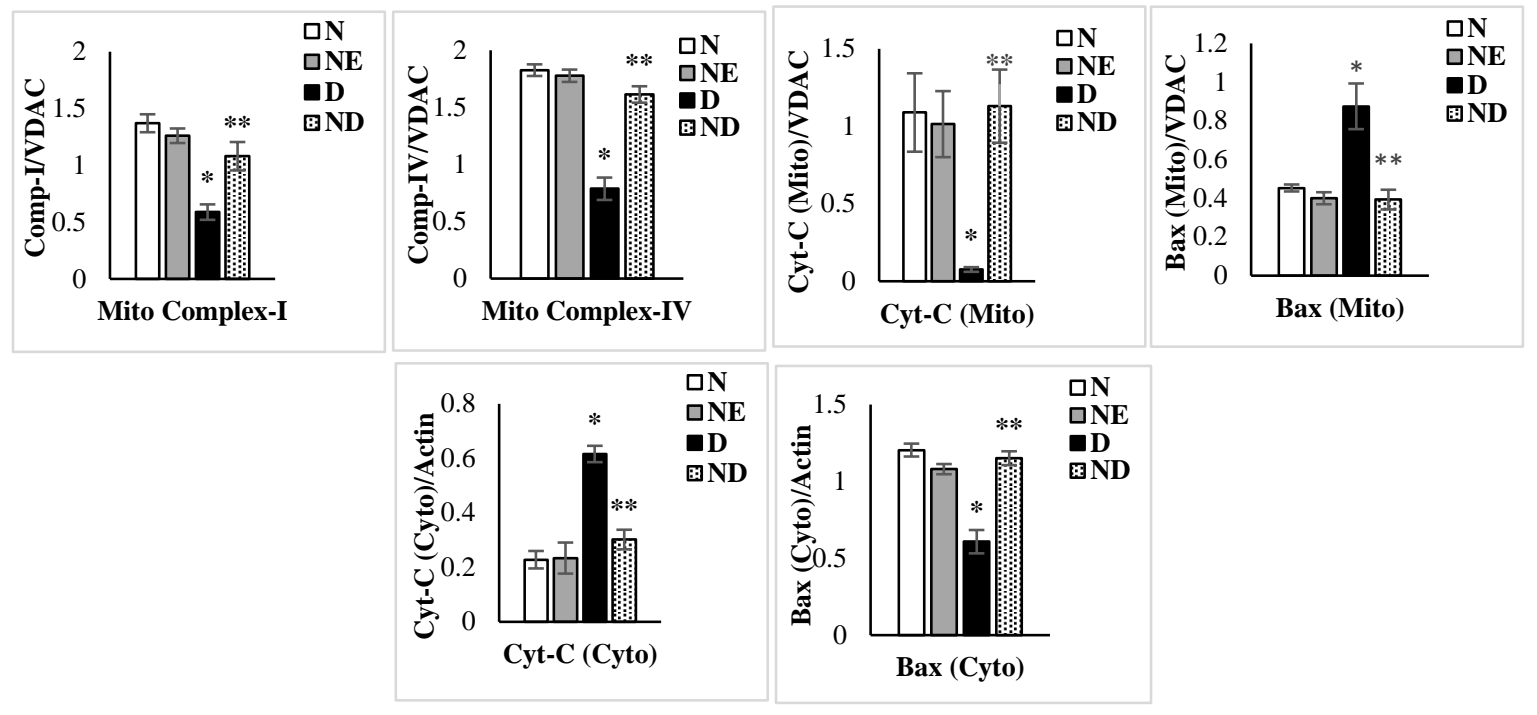

Figure S7. Densitometric analysis for the Western blot analysis of mitochondrial complex-I, Complex-IV, Bax (Mito), cytochrome-C (mito), Bax (Cyto), cytochrome-C (Cyto). The values are expressed as the mean \pm SEM $(\mathrm{n}=3)$; columns not sharing a common symbol $(*, * *)$ differ significantly with each other $(* \mathrm{P}<0.05$ vs normal control, $* * \mathrm{P}<0.05$ vs DOX control). 


\section{TGF-ß/Collagen/Smad signaling}

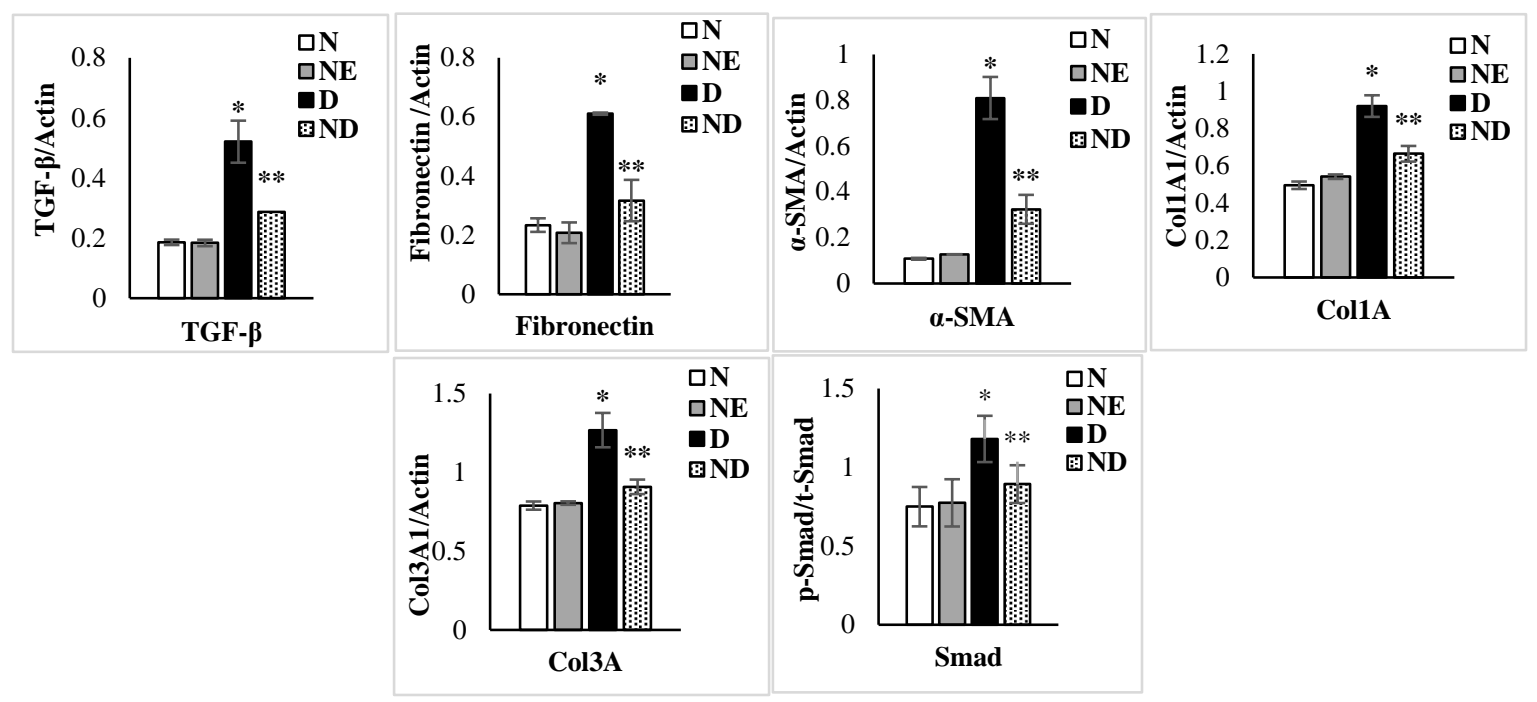

Figure S8. Densitometric analysis for the Western blot analysis of TGF- $\beta$, fibronectin, $\alpha-S M A$, Col1A1, Col3A1, t-Smad2/3 and p-Smad2/3. The values are expressed as the mean $\pm \mathrm{SEM}(\mathrm{n}=3)$; columns not sharing a common symbol $(*, * *)$ differ significantly with each other $(* \mathrm{P}<0.05$ vs normal control, $* * \mathrm{P}<0.05$ vs DOX control). 